\title{
Psychometric property evaluation of a midlife women quality of life questionnaire
}

\author{
Kathleen Forst Putnam \\ Old Dominion University School of Nursing, USA \\ E-mail: kputnam@odu.edu
}

\begin{abstract}
Background: Quality of life in midlife women may be negatively impacted by biopsychosocial factors including midlife developmental tasks and hormonal changes. Many instruments measure physical aspects of menopause, but few specifically measure global quality of life in midlife women within a biopsychosocial perspective.

Objectives: The purpose of this study was to assess the reliability and validity of the Midlife Women Quality of Life Questionnaire (MWQOL).

Methods: The original 30-item MWQOL was piloted with a sample of 166 midlife women. Items were derived from the literature and the investigator's practice experience with this population, which supports the content validity of the instrument. After psychometric evaluation of the first version, 201 midlife women aged 45-64 completed the revised 17-item instrument. Principal component analysis with varimax rotation was used in the factor analysis to determine the construct validity of the MWQOL. Concurrent administration of the Utian Quality of Life (UQOL) instrument was used to determine convergent validity.

Results: Three factors emerged from the MWQOL: physical (Cronbach's alpha 0.82), generativity (Cronbach's alpha 0.82), and resolution (Cronbach's alpha 0.78). Two identical items on the MWQOL and the UQOL ("I feel physically fit") correlated at 0.863 . Additionally, $56.5 \%$ of the variance in the 17 items of the MWQOL was accounted for by these three factors. Pearson's correlation between the MWQOL and the UQOL instrument was significant at .768.

Conclusions: Findings suggest that the MWQOL is a valid and reliable measure of quality of life for a sample of midlife women. Measures that will improve understanding of the psychological, social, and physical health of midlife women could help providers better evaluate midlife women's quality of life and assess the effectiveness of specific interventions aimed at improving it.
\end{abstract}

Keywords: Middle Aged, Quality Of Life, Reliability, Validity, Women's Health.

\section{Introduction}

Midlife is the "perfect storm" for many women, as it represents significant events, such as launching of adult children, arrival of grandchildren, and caring for aging parents, often simultaneously. In women, these events are compounded by developmental tasks and hormonal changes. Although many instruments measure the physical aspects of menopause, it is difficult to find any that measure the quality of life in midlife women from a biopsychosocial perspective. The Midlife Women Quality of Life Questionnaire (MWQOL) was developed to measure not only the physical aspects, but also the transitional and developmental impact of midlife in women. This paper presents the data related to the development and testing of the MWQOL.

\subsection{Background}

According to the U.S. Census Bureau (2013), 42 million women in the United States are between 45 and 64 years of age, comprising $27 \%$ of the population. Life expectancy in 2008 for women in the United States was 80.5 years of age, approximately 5 years longer than reported for men (U.S. National Center for Health Statistics 2010). Additionally, as women grow older, their use of health services increases. By age 65 , at least $96 \%$ of women in one national study reported use of a health service in the past year
(Taylor et al. 2006). Moreover, $92.4 \%$ of women between the ages of 45 and 64 reported using healthcare services in some capacity. What health problems do midlife women experience? According to 2010 data from the Centers for Disease Control and Prevention (CDC), the two leading causes of death in women between the ages of 45 and 64 were cancer and heart disease. In addition, nearly 40 percent of women between the ages of 40 and 59 are obese according to CDC data (Ogden et al. 2013). Obesity, which may be largely preventable through lifestyle changes and health promoting behaviors, increases the risk of death from these diseases. Chronic diseases also lead to financial burden for women. The economic burden of osteoporosis, breast cancer, and cardiovascular diseases is financially significant (Sasser et al. 2005). These potential health issues along with hormonal fluctuations and changes in the family and social structure can have a significant and negative impact on the quality of life of midlife women. Quality of life, as defined by the World Health Organization (WHO), is "individuals' perception of their position in life in the context of the culture and value systems in which they live in relation to their goals, expectations, standards and concerns" (WHO 1993, p. 1). A plethora of quality of life instruments can be found in sources such as the Patient-Reported Outcome and Quality of Life Instruments Database (PROQOLID 2014). A quick search in this database for quality of life instruments for women resulted in 
illness oriented instruments designed to assess specific diseases such as osteoporosis, incontinence, and sexual functioning.

Other instruments focus on physical symptoms during midlife. The Women's Health Questionnaire (WHQ), revised in 2006, is a 23-item instrument that assesses the following six domains: anxiety and depressed mood; well-being; somatic symptoms; memory and concentration; vasomotor symptoms; and sleep problems (Girod et al. 2006). The Menopause Symptom List is a 12-item questionnaire that addresses psychological, somatic, and vasomotor aspects of menopause (Freeman et al. 2003). The MenopauseSpecific Quality of Life (MENQOL) and MENQOL-Intervention questionnaires (Lewis et al. 2005) measure intervention side effects, which may have a negative impact on a woman's quality of life. The Menopause Rating Scale, initially developed in the early 1990s to measure the severity of aging symptoms and their effect upon health-related quality of life, evaluates three independent dimensions of the construct: psychological, somato-vegative, and urogenital (Heinemann et al. 2004).

The Utian Quality of Life instrument (UQOL) was originally developed to assess the "sense of well-being" of women in a treatment study comparing estrogen to a placebo control (Utian et al. 2002). This 23-item instrument measures four quality of life domains: occupational, physical, emotional, and sexual (Utian et al 2002). The UQOL, however, does not incorporate developmental tasks of midlife as defined by Erickson. The authors state that the UQOL is the first pure quality of life measure of a new generation of instruments that can be applied to the menopausal generation (Utian et al. 2002). Although menopause and chronic illness are important midlife experiences and may influence women's perspective on other important life issues, they are not the totality of their experiences. To fully understand the quality of life of U.S. women in midlife, a more comprehensive and holistic measure is needed.

As noted in the discussion above, most of the instruments are more problem focused. Although Utian's instrument measures more than the physical aspects of midlife women, it is not undergirded by a theory as is the MWQOL. Other instruments discussed above focus primarily on the physical symptoms experienced by midlife women. The MWQOL is unique in that it incorporates Erickson's developmental tasks along with physical aspects of midlife in women. This instrument can be utilized in the clinical setting by providers to assess midlife women's overall quality of life.

\subsection{Conceptual framework}

Global quality of life (QOL) generally refers to a sense of wellbeing and self-satisfaction and is unrelated to the presence or absence of physical symptoms (Utian 2006). When quality of life is evaluated in the context of health and disease, it is referred to as health-related quality of life (HRQoL). Health-related quality of life is multidimensional, incorporating physical, mental, emotional, and social functions, and is also related to well-being and the positive aspects of a person's life (Healthy People 2010). One of the Healthy People 2020 objectives focuses on enhancing healthrelated quality of life and well-being (Healthy People 2010).

The framework for the current study is based on two related theories: Engle's (1977) biopsychosocial theory and Erickson's (1963) developmental theory. Engle's (1977) biopsychosocial (BPS) model offered a holistic approach as an alternative to the prevailing biomedical model at the time (Borrell-Carrio et al. 2004). Prior to the turn of the last century, medicine's guiding biomedical model focused on diseases (Smith 2002). The biomedical model assumes diseases to be completely accounted for by measuring biological markers' deviation from the norm, leaving no room within the framework for social, psychological, or behavioral dimensions of illness (Engle 1977). The BPS model guided clinician thinking by incorporating psychosocial components (e.g., personal, family, emotional, community, etc.) with the aspects of the disease, thus linking science and humanism (Smith 2002). The BPS model provides a framework for this MWQOL by incorporating the bio- logical, psychological, and social aspects of midlife women within the questionnaire items.

Erickson (1963) described middle adulthood as the time for generativity versus stagnation. Generativity is the capacity to provide for the next generations (Weiland 1993). Guiding the next generation and being concerned with the future of the world are seen as positive resolutions to the conflict of generativity versus stagnation (Misener et al. 2000). It is not possible to change the past, so midlife offers a chance to create something new for future generations. Using the Engle's BPS model to assess the biological, psychological, and social aspects of midlife women as well as the developmental tasks of midlife provides distinct variables to examine their contribution to quality of life in midlife women.

For many women, midlife is a time that represents tremendous change. Many instruments focus specifically on the physical aspects of midlife, overlooking the developmental and transitional factors occurring simultaneously. The MWQOL differs from other quality of life instruments in that it addresses developmental aspects of midlife women (along with measuring some physical aspects) rather than completely focusing on physical symptoms of menopause. Furthermore, the MWQOL is a theoretically based instrument informed by developmental theory and biopsychosocial theory. Example survey items on the generativity scale supported by developmental theory include "I have gained knowledge" and "I have made a difference." Examples survey items supported by biopsychosocial theory include the following: "I sleep well"; "I am able to solve problems"; and "My job is important." Thus, the purpose of this study was to evaluate the psychometric properties of the MWQOL.

\section{Methods}

Development and testing of the MWQOL occurred in two distinct phases. Phase 1 of development occurred in 2004 during the author's doctoral program as a requirement for an instrument development class. Phase 2 occurred during data collection for the author's dissertation. Each phase of the instrument's development is described.

\subsection{Phase 1: pilot study}

The 30 items on the first version of the MWQOL were generated from the author's 15 years of experience as a women's healthcare nurse practitioner during which time she gathered anecdotal "stories" from many midlife women seen in clinical practice regarding their own perceived quality of life. These 30 items were then reviewed by a panel of experts consisting of 16 midlife women who were nursing $\mathrm{PhD}$ students. The expert panel assessed the items for content and face validity and relevance to the phenomenon of interest, which was quality of life. Several items were refined to improve clarity based on expert reviewer recommendations. All of the original items were retained for inclusion in the first administration of the instrument. Next, the 30-item MWQOL was administered to a random sample of 166 women between ages 45 and 65 who completed the questionnaire in pencil and paper format. Responses were on a 5-point Likert scale with "1" being "strongly disagree" and " 5 " being "strongly agree." The data were analyzed using SPSS version 15. Factor extraction included principal component analysis with varimax rotation. Reliability statistics were also analyzed using Cronbach's alpha.

Initially, two factors emerged using factor analysis in this phase. Eight items on Factor 1 loaded above .498 and were thus retained. Two items were dropped from this factor ("I forgive myself sins of my past" and "I still enjoy intimacy"). Cronbach's alpha for Factor 1 was 0.825 .

Ten items loaded on Factor 2 above .505 and were retained. The two items dropped were "It is important to be involved with the younger generation" and "I am emotionally ready to retire." "I have a good Quality of Life" loaded on Factor 1 and Factor 2 
closely at 0.498 and 0.466 , respectively. Cronbach's alpha for Factor 2 was .753.

The author then reanalyzed a rotated component matrix asking for three factors, keeping the two items originally dropped from Factor 2. This analysis demonstrated the possibility of a third factor with six items, with items loading between 0.381 ("My children, for the most part, make me feel proud of my job as their mother") and 0.718 ("I am able to solve problems easily").

\subsection{Phase 2: formal testing}

Approval of the dissertation study, which focused on formal testing of the instrument, was awarded by the university's Institutional Review Board (IRB). Informed consent consisted of an IRBapproved web page describing the purpose of the study, expected risks and benefits, participant inclusion criterion, and assurance of confidentiality and anonymity. Survey responses were encrypted to protect confidentiality. Each participant chose to click the tab "I agree," which then allowed completion of the survey.

The revised MWQOL consisted of 17 items. Responses were on a Likert scale with "1" being "strongly disagree" and "5" being "strongly agree," with a higher score indicating higher quality of life. Possible scores on the MWQOL range from 17 to 85. All items were worded in the affirmative.

A convenience sample of 201 midlife women participated in formal testing of the MWQOL. Significance criterion alpha was 0.05 , power was set at 0.80 , and effect size was 0.20 . To maximize the power for this statistical analysis, a sample size of 197 was deemed necessary.

The MWQOL was posted online at www.surveymonkey.com Participants were recruited through links posted at Internet sites likely to be visited by midlife women (www.drcarolle.com and www.ourbodiesourselves.org). Additionally, e-mails that provided a direct link to the MWQOL were sent to personal and professional contacts. Participants were asked to complete the MWQOL if they were women between the ages of 45 and 64, fluent in the English language, had Internet access, and were computer literate. Data were analyzed using SPSS version 15 . Preliminary data analysis examined descriptive statistics of the participants (mean, standard deviation, range, and incidence). Demographic and descriptive data were not obtained during the first phase. Principal component analysis with varimax rotation was used to determine the factors of the MWQOL. Cronbach's alpha was used to test for internal consistency reliability of the entire instrument as well as the three subscales. Pearson's Correlation analysis was used to determine concurrent validity with the UQOL instrument.

\section{Results}

Demographic data for Phase 2 participants are found in Table 1. Although this sample was not ethnically comparable to national statistics, it was diverse. Most $(84 \%)$ of the women were employed with $74 \%$ of the participants working full time. The United States Department of Labor, Women's Bureau (2010) reports that of women in the labor force in $2010,73 \%$ of employed women worked full time, while $27 \%$ worked part time.

Approximately $70 \%$ of the study participants described themselves as either naturally or surgically menopausal. The average age of menopause is generally accepted as 50 (Youngkin \& Davis 2013), which is comparable to the mean age of participants in this study.

Factor analysis was used to evaluate the construct validity of the MWQOL (see Table 2). Using principal component analysis with varimax rotation, three distinct factors were identified. These three factors accounted for $56.49 \%$ of variance in the 17 - item instrument. Each of the three factors was given a name by the author based on the type of attributes implied by the items: physical, generativity, and resolution.

Physical Subscale. The physical subscale is comprised of six items loaded on the subscale, which assess physical components of qual- ity of life. These six items loaded between .407 and .907 . Items on this scale included physical fitness, health, sleep, and financial stability.

Generativity Subscale. The generativity subscale has five items that loaded between .505 and .876 . Items on this subscale addressed knowledge, impact on future generations, and wisdom to pass on.

Resolution Subscale. The resolution subscale consists of six items that loaded between .381 and .718 . These items addressed feelings of accomplishment/fulfillment and answering life's questions.

Table 1: Demographic Data for Women in Phase II of Testing the Midlife Women Quality of Life Questionnaire (MWQOL).

\begin{tabular}{|c|c|c|c|}
\hline Participants' Characteristics & $\mathrm{N}(\%)$ & Mean (SD) & Range \\
\hline Age (yrs) & 201 & $52.85(4.78)$ & $46-64$ \\
\hline \multicolumn{4}{|l|}{ Ethnicity } \\
\hline Hispanic or Latino & $5(2.4)$ & & \\
\hline \multicolumn{4}{|l|}{ American Indian or } \\
\hline Alaskan Native & 0 & & \\
\hline Asian & $3(1.4)$ & & \\
\hline Black or African American & $14(6.9)$ & & \\
\hline $\begin{array}{l}\text { Native Hawaiian or } \\
\text { other Pacific Islander }\end{array}$ & 0 & & \\
\hline White & $178(88.5)$ & & \\
\hline \multicolumn{4}{|l|}{ Employment Status } \\
\hline Working full time & 148 (73.6) & & \\
\hline Working part time & $26(12.9)$ & & \\
\hline Not working by choice & $11(5.4)$ & & \\
\hline Not working due health reasons & $5(2.4)$ & & \\
\hline Not working due to lay-off & $3(1.5)$ & & \\
\hline Retired & $8(3.9)$ & & \\
\hline \multicolumn{4}{|l|}{ Menstrual Status } \\
\hline Still having periods & $36(17.9)$ & & \\
\hline Perimenopausal & $25(12.4)$ & & \\
\hline Surgical menopause & $57(28.3)$ & & \\
\hline $\begin{array}{l}\text { Menopausal (no menses for } \\
\text { past year) }\end{array}$ & $82(40.7)$ & & \\
\hline
\end{tabular}

Table 2: Factor Loading For Items on the Midlife Women Quality of Life Questionnaire (MWQOL)

\begin{tabular}{lccc}
\hline Item & Physical & Generativity & Resolution \\
\hline I am physically fit & $\mathbf{. 9 0 7}$ & .058 & .081 \\
I have a regular exercise routine & $\mathbf{. 8 1 5}$ & .077 & -.008 \\
I feel as healthy as in high school & $\mathbf{. 7 8 7}$ & .043 & .139 \\
I generally sleep well & $\mathbf{. 6 1 2}$ & .014 & .250 \\
I am attractive to other people & $\mathbf{. 5 2 0}$ & .154 & .536 \\
I am prepared financially to retire & $\mathbf{. 4 0 7}$ & .117 & .388 \\
I have gained knowledge & .023 & $\mathbf{. 8 7 6}$ & -.130 \\
I have made a difference & -.093 & $\mathbf{. 8 4 5}$ & .151 \\
I feel optimistic about future & .333 & $\mathbf{. 7 1 3}$ & .270 \\
I have become wiser with age & .026 & $\mathbf{. 6 7 1}$ & .333 \\
I have good quality of life & .352 & $\mathbf{. 5 0 5}$ & .332 \\
I am able to solve problems & .119 & .130 & $\mathbf{. 7 1 8}$ \\
The world is a better place & .040 & .521 & $\mathbf{. 6 2 1}$ \\
My job is important & .012 & .159 & $\mathbf{. 6 6 6}$ \\
I feel prepared to become elderly & .341 & .145 & $\mathbf{. 5 6 6}$ \\
I am comfortable with myself & .403 & .391 & $\mathbf{. 4 9 6}$ \\
My children make me feel proud & .073 & .010 & $\mathbf{. 3 8 1}$ \\
\hline
\end{tabular}

Extraction Method: Principal Component Analysis.

Rotation Method: Varimax with Kaiser Normalization. Rotation converged in 5 iterations.

The last item in the resolution scale was, "My children for the most part, make me feel proud of my job as their mother." Because some participants may not have children, the choice "does not apply to me" was offered in Phase 2. Of note, 38 participants $(18.5 \%)$ chose "does not apply to me" to this item. This item loaded at .381 on the resolution subscale, lowest of all the items.

Internal Consistency Reliability. Cronbach's alpha was used to assess internal consistency reliability of the MWQOL scale and subscales (see Table 3). The alpha reliability coefficient for the MWQOL was quite strong at 0.87 . The Cronbach's alpha for the physical and generativity subscales was 0.82 , and Cronbach's alpha for the resolution subscale was 0.78 . This suggests that the entire instrument as well as each of the subscales are reliable based on the internal consistency of the items. 
Table 3: Internal Consistency Reliability of the Midlife Women Quality of Life Questionnaire (MWQOL)

\begin{tabular}{lll}
\hline Subscale/Instrument & Cronbach's Alpha & Number of Items \\
\hline Generativity & .821 & 5 \\
Physical & .822 & 6 \\
Resolution & .779 & 6 \\
MWQOL & .87 & 17 \\
\hline
\end{tabular}

The participants in this study scored an overall mean of 66.75 of a possible $85(\mathrm{SD}=9.6)$ with a range of 35-85. The Cronbach's alpha on the overall MWQOL was 0.87 . Scores on each of the subscales are as follows:

Physical: The mean score of the physical subscale, which contains six items, was 19.64 with a range of 7-30. The mean item mean was 3.27, which was the lowest item mean for the overall MWQOL ( $\mathrm{SD}=5.23)$. Scores ranged from 7 to 30. Cronbach's alpha reliability on the physical scale was 0.82 . Higher scores indicate higher quality of self-perceived physical health, healthy lifestyle, and financial stability.

Generativity: The mean score of the generativity subscale, which contains five items, was 22.7 with a range of 5-25. The mean item mean was 4.54 , which was the highest item mean for the overall MWQOL $(\mathrm{SD}=2.86)$. Cronbach's alpha reliability on the generativity scale was 0.82 . Higher scores indicate higher selfperceived satisfaction at midlife, making it possible to contribute to the next generation.

Resolution: The mean score of the resolution subscale, which contains six items, was 24.4 (SD 3.75) with a range of 9-30. The mean item mean was 4.04. Cronbach's alpha reliability on the resolution scale was 0.78 . Higher scores indicate increased sense of accomplishment and fulfillment and increased comfort with becoming older.

Concurrent Validity. The UQOL instrument was used to determine concurrent validity of the MWQOL. The UQOL was developed with the assumption that quality of life refers to a "sense of well-being." The primary objective in the development of this instrument was to evaluate quality of life in peri-and postmenopausal women at baseline and track overall changes over time (Utian et al. 2002). The UQOL has 23 items that contain four subscales: occupational, health, emotional, and sexual aspects of quality of life. Cronbach's alpha for the entire instrument is 0.83 . Each question is answered on a 5-point Likert-type scale with negative item scores reversed. Subscale and overall scores are the sum of the items (Utian et al. 2002).

Concurrent administration of the UQOL with the MWQOL demonstrated a correlation of $r=.768(p<0.01)$. The subscales of each instrument were significantly correlated with the exception of the UQOL sexual subscale and the MWQOL generativity and resolution subscales (see Table 4). Of interest, the UQOL and the MWQOL each had an identical item ("I feel physically fit"), which correlated at .86.

Table 4: Pearson's Correlation between the Midlife Women Quality Of Life Questionnaire (MWQOL) and the Utian Quality of Life Instrument (UQOL).

\begin{tabular}{lllll}
\hline & MWQOL & Generativity & Physical & Resolution \\
\hline UQOL & .768 & .384 & .712 & .671 \\
Health & .727 & .294 & .838 & .470 \\
Sexual & .202 & $.110(\mathrm{p}=.124)$ & .241 & $.134(\mathrm{p}=.061)$ \\
Occupational & .583 & .379 & .415 & .610 \\
Emotional & .579 & .298 & .500 & .545
\end{tabular}

Emotional $.579 \quad .298 \quad .500 \quad .545$ cated.

\section{Discussion}

The overall purpose of this study was to develop and test an instrument that could measure the quality of life in midlife women. The MWQOL is different from other quality of life instruments because the focus is not primarily on physical symptoms of midlife women. This instrument includes psychosocial and develop- mental aspects of midlife women's lives in addition to certain physical aspects.

The MWQOL has been deemed reliable and valid, both in the pilot and initial formal testing. Factor analysis clearly demonstrated three scales of the MWQOL, with Cronbach's alpha coefficients ranging from .78 to .82. Cronbach's alpha coefficient for the overall instrument was .87 . Convergent validity was supported by a strong correlation with the UQOL of $.77(\mathrm{p}<0.01)$. The sexual scale of the UQOL was significantly correlated with the physical scale of the MWQOL, which is not surprising due to the physical nature of sexuality. The sexual scale of the UQOL did not significantly correlate with the generativity and the resolution scales of the MWQOL, which would be expected because of the non-physical nature of generativity and resolution.

Data were not collected related to socioeconomic status, religion, or educational levels; thus, it is not known whether women may report different qualities of life based on these variables.

\subsection{Limitations}

Survey methodology, especially data collection over the Internet, poses a sampling limitation. Participants in this study were selfselected and may have better represented women who had achieved higher educational and socioeconomic status by virtue of having computer access and frequenting the sites where the survey was posted. Selection bias limits generalizability because participants in an Internet-based study are different from the general population, as those who cannot afford a computer are less likely to participate (Strickland et al. 2003). Most participants were Caucasian; as such, generalization of results to other ethnicities should be made with caution. Using a true random sample would likely have increased the representativeness of the sample, thereby reducing bias and improving generalizability. Data fraud (Strickland et al. 2003) may affect validity as the same participant could potentially complete the survey multiple times from different web addresses. The survey design did not prevent multiple submissions by a respondent. In addition, respondents were assumed to be midlife women; the sample may have included respondents who did not meet these inclusion criteria as they self-selected into the study.

\subsection{Implications for nursing}

The MWQOL, a brief theory and evidence-based survey, can be used by healthcare providers to assess the quality of life of all midlife women. Midlife women have multiple roles in our society, often launching young adult children as well as caring for aging parents. Additionally, midlife is a time in life of physical and hormonal transition. Because no quality of life instruments that address the developmental aspects of midlife women were discovered in the literature, the MWQOL may help fill that void. Quality of life has been designated as a goal of Healthy People 2020 (2010); thus, the MWQOL may serve as a meaningful instrument for identifying women at risk for meeting the goal of improving quality of life. The MWQOL can easily be used to assess the effectiveness of interventions aimed to improve quality of life in midlife women such as hormone replacement therapy. Additionally, this instrument can also be used to educate clinicians about quality of life in midlife women.

\section{Acknowledgements}

The author wishes to thank Dr. Jaime Forst, Dr. Debra Lyons, Dr. Jeanne Salyer, Dr. Judy Lewis, and Dr. Janet Younger for their mentorship. The author also wishes to thank Dr. Mona N. Wicks, Professor, University of Tennessee Health Science Center College of Nursing, for her review of this paper and Ms. Sarah Spangler for editorial advice. 


\section{References}

[1] U.S. Census Bureau, Current Population Survey, Annual Social an Economic supplement (2013) Population by age and sex, 2012. Available at: http://www.census.gov/population/age/data/2012comp.html. Accessed May 25, 2014

[2] U.S. National Center for Health Statistics (2010) Life expectancy, by sex, age, and race: 2008. National Data for 2008, 59 (2). Available at: http://cdc.gov/nchs/deaths.htm. Accessed May 25, 2014.

[3] Taylor A, Larson S, \& Correa-de-Araujo R (2006) Women's health care utilization and expenditures. Women's Health Issues, 16 66-79. http://dx.doi.org/10.1016/j.whi.2005.11.001.

[4] Centers for Disease Control and Prevention, National Center for Injury Prevention and Control (2010) ten leading causes of death among women aged 18 and older, by age. Available at: http://www.cdc.gov/injury/wisqars. Accessed July 7, 2013.

[5] Ogden C, Carroll M, Kit B, Flegal K (2013) Prevalence of obesity among adults: United States, 2011-2012. National Center for Health Statistics Data Brief, 131. Available at: http://www.cdc.gov/nchs/data/databriefs/db131.pdf. Accessed May 25, 2014.

[6] Sasser A, Rousculp M, Birnbaum H, Oster E, Lufkin E, \& Mallet, D (2005) Economic burden of osteoporosis, breast cancer, and cardiovascular disease among postmenopausal women in an employed population. Women's Health Issues, 15 (3), 97-108. http://dx.doi.org/10.1016/j.whi.2004.11.006.

[7] WHO Division of Mental Health (1993) WHO-QOL Study Protocol: The Development of the World Health Organization Quality of Life Assessment Instrument (MNG/PSF/93). World Health Organization, Geneva.

[8] PROQOLID: Patient-Reported Outcome and Quality of Life Instruments Database (2014). Available at: http://www.proqolid.org/. Accessed May 27, 2014.

[9] Girod I, de la Loge C, Keininger D, \& Hunter M (2006) Developmen of a revised version of the Women's Health Questionnaire. Climacteric, 9 (1), 4-12. http://dx.doi.org/10.1080/13697130500487372.

[10]Freeman E, Sammel M, Liu L, \& Martin P (2003) Psychometric properties of a menopausal symptom list. Menopause, 10 (3), 258-65. http://dx.doi.org/10.1097/00042192-200310030-00014.

[11]Lewis J, Hilditch J, \& Wong C (2005) Further psychometric property development of the Menopause-Specific Quality of Life questionnaire and the development of a modified version, MENQOL-Intervention questionnaire. Maturitas, 50 (3), 209-21. http://dx.doi.org/10.1016/j.maturitas.2004.06.015.

[12]Heinemann K, Ruebig A, Potthoff P, Schneider H, Strelow F, Heinemann L, \& Thai D (2004) The menopause rating scale (MRS) scale: A methodological review. Health and Quality of Life Outcomes, 2, 45 http://dx.doi.org/10.1186/1477-7525-2-45.

[13]Uitan W, Janata J, Kingsberg S, Schluchter M, \& Hamilton J. (2002) The Utian Quality of Life (UQOL) Scale: Development and validation of an instrument to quantify quality of life through and beyond menopause. Menopause: The Journal of the North American Menopause Society, 9 (6), 402-410. doi: 10.1097/01. http://dx.doi.org/10.1097/01.

[14]Utian W (2006) Hormones and quality of life after surgical menopause. Journal of Women's Health, 15 (8). http://dx.doi.org/10.1089/jwh.2006.15.975.

[15]Healthy People 2020 Foundation Health Measure Report. HealthRelated Quality of Life and Well-Being, Revised November 2010. Available http://www.healthypeople.gov/2020/about/DefaultPressRelease.pdf. Accessed May 15, 2014

[16]U.S. Department of Health and Human Services. HHS announces the nation's new health promotion and disease prevention agenda. Available at: www.hhs.gov/news. Accessed May 15, 2014

[17]Engle G (1977) the need for a new medical model: A challenge for biomedicine. $\quad$ Science, $196 \quad$ (4286), 129-136. http://dx.doi.org/10.1126/science.847460.

[18]Borrell-Carrio F, Suchman A, \& Epstein R (2004) the biopsychosocial model 25 years later: Principles, practice, and scientific inquiry. Annals of Family Medicine, 2 (6). http://dx.doi.org/10.1370/afm.245.

[19]Smith R (2002) the biopsychosocial revolution: Interviewing and provider-patient relationships becoming key issues for primary care. $\mathrm{J}$ Gen Intern Med, 17 (4), 309-310. http://dx.doi.org/10.1046/j.15251497.2002.20210.x.

[20]Erickson EH (1963) Childhood and Society. Norton, New York.

[21]Weiland S (1993) Erik Erikson: Ages, stages, and stories. Generations, 17 (2), 17.
[22]Misener TR, Phillips KD, \& McGraw E (2000) psychosocial development and health promoting lifestyle. The Journal of Theory Construction \& Testing, 4, 14-19.

[23]United States Department of Labor Women's Bureau. Women in the labor force in 2010. Available at: http://www.dol.gov/wb/factsheets/Qf-laborforce. Accessed February 21,2014

[24] Youngkin EQ, Davis MS, Schadewald DM, \& Juve C. (Eds.) (2013) Women's Health: A Primary Care Clinical Guide ( $4^{\text {th }}$ Ed.). Pearson, New Jersey.

[25] Strickland OL, Moloney MF, Dietrich AS, Myerburg S, Cotsonis GA, \& Johnson RV (2003) Measurement issues related to data collection on the World Wide Web. Advances in Nursing Science, 26, 246-256. http://dx.doi.org/10.1097/00012272-200310000-00003. 